\title{
A Simple Method to Detect SARS-CoV-2 in Wastewater at Low Virus Concentration
}

\author{
Supranee Thongpradit $\mathbb{D D}^{1}{ }^{1}$ Somsak Prasongtanakij $\mathbb{D}^{1},{ }^{1}$ Supanart Srisala, ${ }^{1}$ \\ Yothin Kumsang, ${ }^{1}$ Suwannee Chanprasertyothin ${ }^{10},{ }^{1}$ Pairoj Boonkongchuen, ${ }^{2}$ \\ Dhanesh Pitidhammabhorn, ${ }^{2}$ Parnrudee Manomaipiboon, ${ }^{3}$ Peeraya Somchaiyanon, ${ }^{3}$ \\ Siriwan Chandanachulaka, ${ }^{4}$ Taiyatach Hirunrueng, ${ }^{4}$ \\ and Boonsong Ongphiphadhanakul ${ }^{1,5}$ \\ ${ }^{1}$ Research Center, Faculty of Medicine Ramathibodi Hospital, Mahidol University, Salaya, Thailand \\ ${ }^{2}$ Chakri Naruebodindra Medical Institute, Faculty of Medicine Ramathibodi Hospital, Mahidol University, Salaya, \\ Samut Prakan, Thailand \\ ${ }^{3}$ Health Department, Bangkok Metropolitan Administration, Bangkok, Thailand \\ ${ }^{4}$ Department of Health, Ministry of Public Health, Nonthaburi, Thailand \\ ${ }^{5}$ Department of Medicine, Faculty of Medicine Ramathibodi Hospital, Mahidol University, Salaya, Thailand
}

Correspondence should be addressed to Somsak Prasongtanakij; somsak.pra@mahidol.edu

Received 29 October 2021; Revised 25 January 2022; Accepted 28 January 2022; Published 22 February 2022

Academic Editor: Nidal J. Mahmoud

Copyright (C) 2022 Supranee Thongpradit et al. This is an open access article distributed under the Creative Commons Attribution License, which permits unrestricted use, distribution, and reproduction in any medium, provided the original work is properly cited.

Background. Since its initial appearance in December 2019, coronavirus disease 2019 (COVID-19), caused by severe acute respiratory syndrome coronavirus 2 (SARS-CoV-2), has spread globally. Wastewater surveillance has been demonstrated as capable of identifying infection clusters early. The purpose of this study was to investigate a quick and simple method to detect SARS-CoV-2 in wastewater in Thailand during the early stages of the second outbreak wave when the prevalence of the disease and the virus concentration in wastewater were low. Methods. Wastewater samples were collected from a hospital caring for patients with COVID-19 and from 35 markets, two of which were associated with recently reported COVID-19 cases. Then, samples were concentrated by membrane filtering prior to SARS-CoV-2 detection by RT-qPCR. Results. SARS-CoV-2 RNA was detected in the wastewater samples from the hospital; the Ct values for the N, ORF1ab, and S genes progressively increased as the number of patients admitted to the treatment floor decreased. Notably, the ORF1ab and S genes were still detectable in wastewater even when only one patient with COVID-19 remained at the hospital. SARS-CoV-2 RNA was detected in the wastewater samples from fresh market where COVID-19 cases were reported. Conclusions. Our findings suggest that wastewater surveillance for SARS-CoV-2 is sensitive and can detect the virus even in places with a high ambient temperature and relatively low prevalence of COVID-19.

\section{Background}

Wastewater surveillance for SARS-CoV-2 has been demonstrated to be a feasible and sensitive method for assessing the prevalence and monitoring the transmission of SARS$\mathrm{CoV}-2$ in various countries and situations during the ongoing COVID-19 pandemic. It was initially shown that SARS-CoV-2 can be detected in both untreated [1-5] and treated wastewater [6] in several countries. Similar results from additional studies in multiple geographical areas have led to the United States Center for Disease Control to recommend wastewater surveillance for SARS-CoV-2 [7].

The spread of COVID-19 appears to be lessened by warm and wet weather [3], and there is a negative correlation between temperature and COVID-19 prevalence across countries. Notably, moderate temperature increases to $34^{\circ} \mathrm{C}$ can disrupt the structure of SARS-CoV-2, while humidity has very little impact [8]. For the related virus, severe acute respiratory syndrome (SARS), UV irradiation of $>90 \mu \mathrm{w} /$ $\mathrm{cm}^{3}$ to the culture medium for 60 min can completely impair 
viral infectivity [9]. Furthermore, UV radiation has been shown to have a significant association with the incidence of COVID-19, which may help to flatten the epidemic [10]. To date, most studies examining the utilization of wastewater surveillance for SARS-CoV-2 were performed in countries with cold weather and/or a high COVID-19 prevalence. For tropical countries, at least in India during 2020, when the average temperature was 25.78 degrees Celsius $\left({ }^{\circ} \mathrm{C}\right)$ [11], SARS-CoV-2 could be molecularly detected in influent wastewater from a water treatment plant. However, at the time of that study, the prevalence of SARS-CoV-2 in India was very high [12]. Thailand is located in the tropical area where the climate is warm to hot year-round with average temperatures during winter, summer, and rainy season at $26.2^{\circ} \mathrm{C}, 29.7^{\circ} \mathrm{C}$, and $28.2^{\circ} \mathrm{C}$, respectively [13]. Overall, the prevalence of SARS-CoV-2 infection has been relatively low compared to other countries, particularly during the earlier waves of the pandemic. To help facilitate wastewater surveillance in low prevalence areas, we developed and examined in the present study a quick and simple method for detecting SARS-CoV-2 in wastewater in Thailand, where the ambient temperature is high, and the prevalence of reported COVID-19 cases is relatively low during the early stages of the second outbreak wave.

\section{Materials and Methods}

The study was approved by the Institute Biosafety Committee (Protocol ID: MU 2021-002), and wastewater samples potentially containing SARS-CoV-2 were properly processed in accordance with standard biosafety guidelines from the World Health Organization [14].

2.1. Sample Collection. During January and February 2021, at the time of the second COVID-19 outbreak in Thailand, grab samples of wastewater were obtained from Chakri Naruebodindra Medical Institute (CNMI), a hospital treating patients with COVID-19 in Samut Prakan province, Thailand. All wastewater samples were collected downstream to the isolation ward for patients with confirmed COVID-19 and before the influent to a water treatment station. All samples were transported on ice to the laboratory for processing.

During February 2021, after social distancing and the closure of schools and specific crowded areas were implemented during the second wave of the SARS-CoV-2 pandemic in Thailand of which the epicenter was Samut Sakhon province ( $45 \mathrm{~km}$ southwest of Bangkok), sewage wastewater samples were collected from 46 open fresh markets in the Bangkok metropolitan area and in the Thanyaburi district of Pathum Thani province. The first confirmed COVID-19 case in Pathum Thani province, part of outer northern Bangkok, was found at the Pornpat market and officially reported on 22 December 2020. In the period from 4 to 13 January 2021, the SARS-CoV-2 infection rate rose to $1.31 \%$ (45 of 3,432 people from the Pornpat and Suchart markets tested positive for SARS-CoV-2 infection). The markets were closed during this outbreak but reopened on 16 January. The second
COVID-19 outbreak started on 7 February, when another positive SARS-CoV-2 test result was reported. A period of "Active Case Finding" then began, spanning from 9 to 16 February 2021, during which 3,931 people at the Pornpat and Suchart markets were tested for SARS-CoV-2 infection. The infection rate rose to $8.37 \%$ (343 of 3,931). On 17 February, 14 waste water samples were collected from three local markets: Pornpat market, Suchart market, and Rangsit Market. During the sampling period, the Pornpat market and Suchart market had reported outbreaks, whereas the Rangsit market did not.

Pornpat market wastewater samples (P1-P4) were collected from the sewage pipeline network around the four corners of the market. Pornpat market samples were also collected from two water sampling sites (P50P6) in the Rangsit canal to check for contamination and from another two sites (P7-P8) at sewage pipelines from dwellings next to the Pornpat market. For the Suchart market, two wastewater samples (S1-S2) were collected from the sewage pipeline in the market, and another sample (S3) was collected from the Rangsit canal. For the Rangsit market, three waste water samples (R1-R3) were collected from the sewage pipeline network that passed through the middle of the market (Supplement Figure S1).

Grab samples of wastewater $(500 \mathrm{~mL} / \mathrm{sample})$ were collected in clean plastic bottles from the wastewater drainage/sewage management system associated with each market and transported on ice to the laboratory, where they were stored at $4^{\circ} \mathrm{C}$ until use in further analysis.

2.2. Sample Preparation and Concentration. The sample preparation and concentrating method was adapted from the work of Ahmed et al. [15]. A subsample (100-400 mL) of each collected grab sample of wastewater was centrifuged at $3000 \times g$ for $10 \mathrm{~min}$ at room temperature to separate out the sediment. The resulting supernatant was then filtered by using a mixed cellulose ester membrane filter (pore size, $0.45 \mu \mathrm{m}$; diameter, $47 \mathrm{~mm}$; GE Healthcare, Chicago, IL, USA) attached to a disposable Millicup ${ }^{\mathrm{TM}}$-FLEX filtration unit (Merck Ltd, Darmstadt, Germany), followed by applying the vacuum pump system to the assembly filtration unit until filtration was complete. Subsequently, the membrane filter was removed and placed in a sterile $5 \mathrm{~mL}$ tube. DNA/RNA Shield ${ }^{\mathrm{TM}}(1 \mathrm{~mL})$ and $0.1 \mathrm{~g}$ of ZR BashingBead (Zymo Research, Sigma, Irvine, CA, USA) were added to each tube, after which the tubes were stored at $-80^{\circ} \mathrm{C}$ until use in further RNA isolation.

2.3. RNA Extraction. To elute the viral RNA from the filtered mixed cellulose ester membrane, the preparation solution was first mixed 10 times $(60 \mathrm{~s}$ each) with a vortex mixer at near maximum speed. After being mixed, $400 \mu \mathrm{L}$ of the solution was transferred into a new nuclease-free tube. The viral RNA was then extracted by using the viral RNA mini kit (Qiagen, Hilden, Germany) in accordance with the manufacturer's protocol. The concentration and purity of the extracted RNA were determined by using a Nanodrop ${ }^{\mathrm{TM}}$ (Thermo Fisher Scientific, Waltham, MA, USA). The 
absorbance readings at $260 \mathrm{~nm}$ and $280 \mathrm{~nm}$ (260/A280 ratios) are commonly used to determine the purity of nucleic acid. A general acceptable range for $260 / 280$ ratios is $1.9-2.1$.

\subsection{SARS-CoV-2 Detection and Quantification. For SARS-} CoV-2 detection in wastewater samples, RT-qPCR assays were performed and analysed with a TaqMan ${ }^{\mathrm{TM}} 2019 \mathrm{nCoV}$ Assay Kit v1 (Thermo Fisher Scientific), which detects the following three SARS-CoV-2 viral genes: ORF1ab, spike (S), and nucleocapsid (N). Each $25 \mu \mathrm{L}$ RT-PCR reaction mixture contained $6.25 \mu \mathrm{L}$ of 4x TaqPath ${ }^{\mathrm{TM}} 1$-Step RT-qPCR Master Mix, $1.25 \mu \mathrm{L}$ of COVID19 Real-Time PCR Assay Multiplex, $12.5 \mu \mathrm{L}$ of nuclease-free water, and $5 \mu \mathrm{L}$ of extracted RNA. TaqPath ${ }^{\mathrm{TM}}$ COVID-19 control (Thermo Fisher Scientific) was used as a positive control, MS2 Phage control was used as an internal positive control, and DNase/RNase-free water was used as a negative control. Each RT-qPCR experiment was performed on a ViiA 7 Real-Time PCR instrument (Applied Biosystems, Waltham, MA, USA) using the following thermocycling conditions: $2 \mathrm{~min}$ at $25^{\circ} \mathrm{C}$ for UNG incubation to eliminate amplicon carryover, $15 \mathrm{~min}$ at $50^{\circ} \mathrm{C}$ for reverse transcription, $2 \mathrm{~min}$ at $95^{\circ} \mathrm{C}$ for predenaturation, and 40 cycles of $3 \mathrm{~s}$ at $95^{\circ} \mathrm{C}$ and $30 \mathrm{~s}$ at $60^{\circ} \mathrm{C}$ for denaturation, annealing, and extension. After every amplification cycle, the fluorescence intensity was measured at $60^{\circ} \mathrm{C}$. Results were classified as positive for SARS-CoV-2 detection if they included positive results, defined as cycle threshold $(\mathrm{Ct})<37$, for two or more SARS-CoV-2 target genes. An individual assay result of $37 \leq \mathrm{Ct} \leq 40$ was considered to be inconclusive; samples with inconclusive results were repeated. A 10-fold serial dilution of TaqPath ${ }^{\mathrm{TM}}$ COVID-19 control amplification was performed to generate the standard curve used for SARS-CoV-2 quantification.

2.5. Sensitivity of SARS-CoV-2 Detection in Wastewater. To determine the lower limit of detection of the assay kit used in this study, we established a standard curve with 10fold serial dilutions of 2019-nCoV DNA control from the RT-qPCR Kit, ranging from $1 \times 10^{4}-1$ copies $/ \mu \mathrm{L}$. An inverse linear relationship was generated against each of the three target genes. The mean $\mathrm{Ct}$ values ranging from $26.9 \pm 0.1$ to $35.9 \pm 1.1$ for the ORF1ab gene, $26.7 \pm 0.1$ to $33.6 \pm 0.4$ for the $\mathrm{N}$ gene, and $26.1 \pm 0.1$ to $32.9 \pm 0.6$ for the $\mathrm{S}$ gene corresponded to concentrations of $10^{4}-10^{2}$ copies/ $\mu \mathrm{L}$ (Supplement Table S1).

For the sensitivity of the used method on grab wastewater, left-over grab wastewater samples negative for SARS$\mathrm{CoV}-2$ viral RNA stored at $-80^{\circ} \mathrm{C}$ were pooled and mixed for analysis in a spike study. Seven hundred $\mathrm{mL}$ of the pooled samples was divided into 14 equal aliquots of $50 \mathrm{~mL}$ and processed in duplicate. Two aliquots of no-spike wastewater were autoclaved, to further ensure the absence of SARSCoV-2 RNA in the samples, and were used as blank samples. Ten aliquots were individually spiked with 10 -fold serial dilutions of inactivated culture medium of SARS-CoV-2 with $10 \%$ TRIzol $^{\mathrm{TM}}$ reagent (cat. no. 15596026, Life Technologies Corporation, Carlsbad, CA 92008). Genomic copies (GC) number in all samples was determined by RT-qPCR. Each $50 \mathrm{~mL}$ spiked wastewater aliquot was then concentrated by the method adapted from the work of Ahmed et al. [15] before further RNA extraction and RTqPCR as described in Materials and Methods.

\section{Results}

3.1. Sensitivity of SARS-CoV-2 Detection in Wastewater. Table 1 shows the results of the spike experiments with serially diluted virus culture medium samples into pooled wastewater samples negative for the virus. SARS-CoV-2 could be detected in 15/15 in all seeded samples with $\mathrm{Ct}$ values ranging from $18.28 \pm 0.16$ to $28.60 \pm 0.41$ for the $\mathrm{N}$ gene, $18.94 \pm 0.06$ to $29.13 \pm 0.85$ for the ORF1ab gene, and $19.37 \pm 0.11$ to $29.77 \pm 1.54$ for the $S$ gene, respectively. Overall, the assay was sensitive enough to detect SARS-CoV2 down to $1.63 \pm 0.47,1.20 \pm 0.49$, and $1.20 \pm 1.51$ copies $/ \mathrm{mL}$ for the N, ORF1ab, and S genes, respectively. No virus was detected from all 4 samples extracted from no-spike pooled wastewater with or without being autoclaved before the extraction.

As shown in Table 2, the Ct values for the N, ORF1ab, and $S$ genes progressively increased as the number of patients admitted to the treatment floor decreased. Notably, two out of the three SARS-CoV-2 genes were still detectable in wastewater even when only one patient was present in the COVID19 isolation ward. The ORF1ab and S genes appeared to be more sensitive for detecting the presence of patients with COVID-19 from wastewater. As the number of patients with COVID-19 decreased, the Ct values for both these genes increased. There was a significant correlation between the number of cases and the $\mathrm{Ct}$ values of the ORFlab gene $(r=-0.99, p<0.05)$, whereas such correlation for the $S$ gene tended to reach statistical significance $(r=-0.98, p=0.06)$. For the $S$ genes, there were only 2 detectable samples, and the statistical analysis was not performed.

3.2. SARS-CoV-2 Surveillance in Wastewater from Fresh Markets in Bangkok. Wastewater samples were collected from 46 open fresh markets in the Bangkok metropolitan area. The daily number of reported cases in Bangkok during this period is shown in Figure 1, and a map of the markets from which the wastewater samples were collected is in Supplement Figure S2. All samples collected and tested during this period were found to be negative for SARS-CoV-2. There was no major outbreak of SARS-CoV-2 infection in Bangkok for up to 1 month after the wastewater collection period.

3.3. SARS-CoV-2 Surveillance of Wastewater from Fresh Markets in Pathum Thani Province. The SARS-CoV-2 RNA detection results for these samples are presented in Table 3. SARS-CoV-2 RNA was detected in three of the four samples (P1-P2, P4) from the Pornpat market sewage pipeline network, but the fourth sample (P3) produced an inconclusive result. Only the ORF1ab gene was detected in all four samples from the Pornpat market sewage pipeline network (P1-P4); similarly, this gene was also the only one detected in both of the sewage pipeline samples from the Suchart market (S1-S2). Furthermore, SARS-CoV-2 RNA was 
TABLE 1: SARS-CoV-2 detection from pooled wastewater negative for SARS-CoV-2 with and without SARS-CoV-2 spike.

\begin{tabular}{lcccccc}
\hline \multirow{2}{*}{ SARS-CoV-2 seeded (GC) } & \multicolumn{2}{c}{$\mathrm{N}$} & \multicolumn{2}{c}{ ORF1ab } & \multicolumn{2}{c}{ S } \\
& Mean Ct + SD & Copies/mL \pm SD & Mean Ct + SD & Copies/mL \pm SD & Mean Ct + SD & Copies/mL \pm SD \\
\hline $2 \times 10 \mathrm{e} 4$ & $18.28 \pm 0.16$ & $4,821.14+1,250.18$ & $18.94 \pm 0.06$ & $5,081.59+1,785.77$ & $19.37 \pm 0.11$ & $9,031.87+4,093.59$ \\
$2 \times 10 \mathrm{e} 3$ & $19.85 \pm 0.08$ & $1,145.74+58.11$ & $20.04 \pm 0.42$ & $546.70+7.08$ & $19.65 \pm 0.13$ & $893.20+12.93$ \\
$2 \times 10 \mathrm{e} 2$ & $22.33 \pm 0.10$ & $114.03+7.79$ & $23.29 \pm 0.16$ & $86.57+3.94$ & $22.54 \pm 0.24$ & $92.21+0.82$ \\
$2 \times 10 \mathrm{e} 1$ & $24.39 \pm 0.08$ & $12.07+1.51$ & $27.44 \pm 2.68$ & $11.72+15.74$ & $26.79 \pm 2.69$ & $11.89+17.23$ \\
$2 \times 10 \mathrm{e} 0$ & $28.60 \pm 0.41$ & $1.63+0.47$ & $29.13 \pm 0.85$ & $1.20+0.49$ & $29.77 \pm 1.54$ & $1.63+1.51$ \\
No-spike $^{\mathrm{a}}$ & UD & - & UD & - & UD & - \\
No-spike $^{\mathrm{b}}$ & UD & - & UD & - & UD & - \\
\hline
\end{tabular}

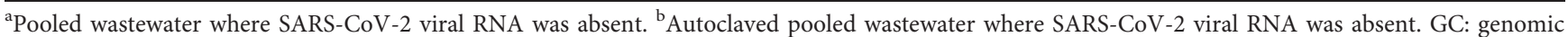
copies. UD: undetermined.

TABLE 2: Detection of SARS-CoV-2 in wastewater from a hospital where patients with COVID-19 were treated.

\begin{tabular}{|c|c|c|c|c|c|}
\hline \multirow{2}{*}{ Date } & \multirow{2}{*}{ Number of admitted patients } & \multirow{2}{*}{ Number of estimated people in the wastewater catchment } & \multicolumn{3}{|c|}{ Ct value } \\
\hline & & & $\mathrm{N}$ & ORF1ab & S \\
\hline 12 Jan 2021 & 18 & 866 & 26.51 & 27.25 & 27.63 \\
\hline 19 Jan 2021 & 4 & 839 & 31.94 & 33.89 & 32.01 \\
\hline $26 \operatorname{Jan} 2021$ & 3 & 847 & UD & 33.43 & 33.65 \\
\hline 27 Jan 2021 & 1 & 848 & UD & 35.74 & 36.51 \\
\hline 28 Jan 2021 & 0 & 842 & UD & UD & UD \\
\hline
\end{tabular}

UD: undetermined.

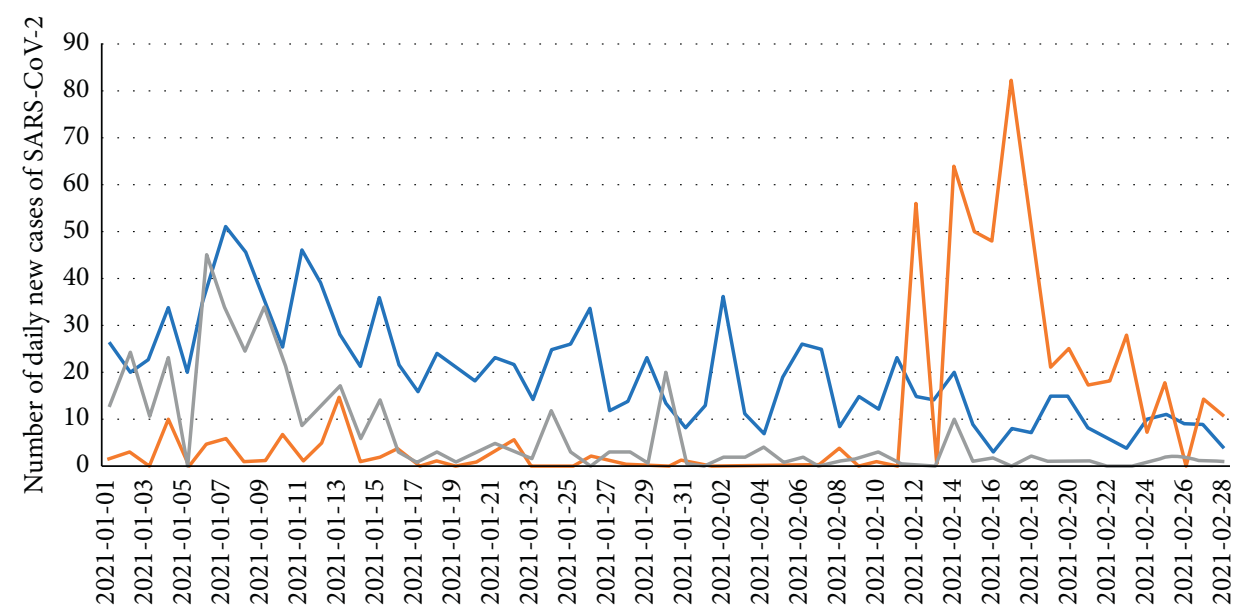

Date

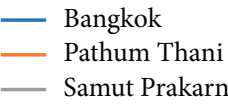

FIGURE 1: Number of daily new cases of SARS-CoV-2 infection in the Bangkok metropolitan (blue line), Pathum Thani province (orange line), and Samut Prakan province (grey line) from January to February 2021. Data obtained from the Department of Disease Control, Ministry of Public Health, Thailand [16].

detected in the samples from sewage pipelines from dwellings next to the Pornpat market (P7-P8). In contrast, SARS-CoV-2 genetic material was not detected in any samples from the Rangsit canal (P4-P5, S3) or the Rangsit market (R1-R3).

\section{Discussion}

In the present study, we demonstrated the performance of a quick and simple method for detecting SARS-CoV-2 in wastewater in Bangkok and the surrounding areas despite the high ambient temperature and low prevalence of COVID-19 in this location. Previous studies, such as those performed in the Netherlands [2] and Australia [1], have applied various methods of filtering, concentrating, and PCR to detect SARSCoV-2 in sewage samples. Here, we chose to use membrane filtering and concentrating, which have been demonstrated as reliable methods for detecting SARS-CoV-2.

Recent studies in many countries identified SAR-CoV2 viral RNA in wastewater, sewage sludge, and river water 
TABLE 3: Detectability of SARS-CoV-2 in samples from various markets in Pathum Thani province.

\begin{tabular}{|c|c|c|c|c|c|}
\hline \multirow{2}{*}{\multicolumn{2}{|c|}{ Location }} & \multicolumn{4}{|c|}{ Ct value } \\
\hline & & $\mathrm{N}$ & ORF1ab & S & Result \\
\hline \multirow{8}{*}{ Pornpat market } & $\mathrm{P} 1$ & 34.21 & 31.89 & 33.98 & Positive \\
\hline & $\mathrm{P} 2$ & 32.24 & 30.94 & 34.85 & Positive \\
\hline & $\mathrm{P} 3$ & UD & 33.35 & UD & Inconclusive \\
\hline & $\mathrm{P} 4$ & UD & 33.83 & 36.97 & Positive \\
\hline & P5 & UD & UD & UD & Negative \\
\hline & P6 & UD & UD & UD & Negative \\
\hline & P7 & 33.39 & 30.46 & 31.32 & Positive \\
\hline & P8 & 33.96 & 31.77 & 33.92 & positive \\
\hline \multirow{3}{*}{ Suchart market } & $\mathrm{S} 1$ & UD & 36.51 & UD & Inconclusive \\
\hline & $\mathrm{S} 2$ & 36.41 & 34.81 & UD & Positive \\
\hline & S3 & UD & UD & UD & Negative \\
\hline \multirow{3}{*}{ Rangsit market } & $\mathrm{R} 1$ & UD & UD & UD & Negative \\
\hline & $\mathrm{R} 2$ & UD & UD & UD & Negative \\
\hline & $\mathrm{R} 3$ & UD & UD & UD & Negative \\
\hline
\end{tabular}

UD: undetermined.

using two or more genetic parts of the viral genome [17]. Three different SARS-CoV-2 genomic regions, Orflab gene, $\mathrm{N}$ gene, and $\mathrm{S}$ gene, were used to detect virus RNA in wastewater in Chile [18], India [12,19], and Germany [20]. The studies revealed that the genome copy number of the viruses increased progressively, corresponding to an increase in the estimated number of virus infections in the community and the affected area. Furthermore, partly similar to our study, the Ct values have been demonstrated to negatively correlate to the effective reproduction number (Rt), daily COVID-19 hospitalization with a 33-day time delay, and daily changes in percent positivity among tested samples [21].

As for now, there are no assay targets recommended for identifying SARS-CoV-2 in wastewater. Several SARS-CoV2 gene targets were commonly used for RT-qPCR detection such as N, E, S, RNA-dependent RNA-polymerase (RdRp, also known as nsp12), and open reading ORF1ab [22]. Bivins et al. reviewed the SARS-CoV2 RNA wastewater surveillance about the variability of basic and essential information for reverse transcription-quantitative PCR (RT-qPCR) assay parameters such as SARS-CoV-2 gene target, the standard curve parameters of $y$-intercept, slope and/or efficiency, and r2 value. They screened 208 RT-qPCR assays from 46 preprint and 36 peer-reviewed publications and found the assays targeting $130 \mathrm{~N}$ gene, 25 targeted ORF1, 23 targeted the E gene, 19 targeted RdRp, and 10 targeted the $\mathrm{S}$ gene, whilst one did not report any target molecule. Quantification SARS-CoV-2 RNA in wastewater targeting the US CDC N1 and N2 accounted for $45 \%$ of the RT-qPCR assays reported and $\mathrm{N} 1$ was tested more frequently (39\%) than the US CDC N2 (32\%) [23]. Therefore, we examined three different genes of SARS-CoV-2, ORF1ab, $\mathrm{N}$ protein genes and $\mathrm{S}$ protein genes, using the commercial PCR test kits, TaqMan ${ }^{\mathrm{TM}} 2019$ nCoV Assay Kit v2 (Life Technologies Corporation, USA) for SARS-CoV-2 diagnosis of the virus genome in wastewater sample. This assay kit has been approved for marketing in Thailand by the Food and Drug Administration (FDA) Thailand under an evaluated for emergency use authorization (EUA) since June 4th, 2020 [24].
This study protocol allowed SARS-CoV-2 to be detected even when the number of apparently infected individuals in the wastewater catchment area was as low as one. Interestingly, although the RT-qPCR Ct values were related to both the absolute number and the percentage of persons infected with SARS-CoV-2 in the catchment area, the Ct values were more closely related to the absolute number of infected persons. This result is likely a consequence of the high sensitivity of RT-qPCR, which can detect SARS-CoV-2 RNA in samples with as little as 21 copies per reaction for the $\mathrm{N} 1$ gene [25]. Our findings also suggest that, at the building level, the amount of daily wastewater production may not only be related to the number of people using the sewage system.

Importantly, our study confirms that SARS-CoV-2 can be detected in wastewater from a number of areas in Thailand, where the ambient temperature is high and there is abundant sunshine all year round and the average temperature obtained from the Thai Meteorological Department [13] during collection of samples is 25.7 and 28.4 for January and February 2021, respectively. The average daily maximum UV index is 10 in January and up to 12 in February.

Our finding is in line with a report from India, where the weather is relatively similar to that of Thailand; SARS-CoV-2 could be detected in wastewater from India during the early phase of the SARS-CoV-2 pandemic [12]. In that study, water was sampled from a water treatment plant in Ahmedabad, for which the catchment areas included a hospital that was treating patients with COVID-19. Ahmedabad is located close to the equator and has a high ambient temperature, averaging $27.1^{\circ} \mathrm{C}$ [26]. The number of COVID-19 cases in Ahmedabad during the course of that study was approximately 5,000-10,000, which is much higher than the COVID-19 prevalence in Thailand during the present study. A few other countries in Asia have also reported the successful detection of SARS-CoV-2 in wastewater. In Japan, during March to May 2020, wastewater samples were collected from several water treatment plants, and the SARS-CoV-2 detection frequency was found 
to increase with the number of reported COVID-19 cases [27]. Interestingly, SARS-CoV-2 could be detected even when the number of COVID-19 cases was $<1.0$ per 100,000 people. Another study with sample sources and a setting similar to ours identified SARS-CoV-2 in wastewater from a hospital in China [28], although unlike our study, the number of COVID-19 cases in China at the time of that study was very high. Our study is in line with a report from Wannigama et al. [29], who reported the detectability of SARS-CoV-2 in wastewater in Bangkok and suggested that wastewater can be used as a complementary source for detecting the viral RNA and predicting upcoming outbreaks. They monitor SARSCoV-2 RNA in wastewater prior to the second outbreak in Thailand during the rainy season and winter.

In the present study, RT-qPCR performed using a $\mathrm{TaqMan}^{\mathrm{TM}}$ 2019-nCoV Assay Kit v2 was used to detect three SARS-CoV-2 target genes: ORF1ab, S, and N. Our results demonstrate that the ORF1ab gene was detected at a higher frequency compared with the $\mathrm{N}$ and $\mathrm{S}$ genes. Overall, eight out of eight (100\%) ORF1ab gene assays produced positive amplifications, whereas only five out of eight (62.5\%) assays for the $\mathrm{N}$ and $\mathrm{S}$ genes did so; the average $\mathrm{Ct}$ values were $32.95 \pm 2.06,34.04 \pm 1.53$, and $34.21 \pm 2.03$ for the ORF1ab, $\mathrm{N}$, and S genes, respectively. A previous study of this RT-qPCR kit reported differences in its sensitivity for detecting different SARS-CoV-2 target genes in nasopharyngeal swabs from 98 COVID-19-positive patients. The highest detection sensitivity was for the $\mathrm{N}$ gene $(76.5 \%$; $95 \%$ confidence interval: $66.9 \%-$ $84.5 \%)$, followed by the $\mathrm{S}$ gene (70.4\%), and the ORF1ab gene (65.3\%) [30]. Using the RNA-dependent RNA polymerase (RdRP), $\mathrm{N}$, and $\mathrm{S}$ genes as targets, another study on wastewater samples found that the amplification efficiencies were $93 \%, 87 \%$, and $84 \%$, respectively [31]. The sensitivity differences among gene targets and different studies have been suggested to reflect differences in the abundance of SARSCoV-2 in wastewater according to the community COVID-19 pandemic level and the methodologies applied for viral RNA detection, including those for virus concentration, RNA extraction, and RT-qPCR assay [32].

\section{Conclusions}

(i) The membrane filtering-based method described here is a rapid, extremely simple, and sensitive approach for the detection of SARS-CoV-2 in wastewater from areas with low numbers of COVID-19 cases

(ii) Wastewater monitoring for SARS-CoV-2 is sensitive and can detect the virus even in places with a high ambient temperature and relatively low prevalence of COVID-19

(iii) This data is useful for community SARS-CoV-2 surveillance and prevention of the spread of coronavirus disease or COVID-19

\section{Data Availability}

The data used to support the finding of this study are included within the article.

\section{Ethical Approval}

The study was approved by the Institute Biosafety Committee (protocol ID: MU 2021-002), and wastewater samples potentially containing SARS-CoV-2 were properly processed in accordance with standard biosafety guidelines from the World Health Organization.

\section{Conflicts of Interest}

The authors declare conflicts of interest.

\section{Authors' Contributions}

Supranee Thongpradit (S.T.), Somsak Prasongtanakij (S.P.), and Supanart Srisala (S.S.) contributed to samples collection and preparation, performed experiments, and wrote the manuscript. Yothin Kumsang (Y.K.), Suwannee Chanprasertyothin (S.C1.), Pairoj Boonkongchuen (P.B.), Dhanesh Pitidhammabhorn (D.B.), Parnrudee Manomaipiboon (P.M.), Peeraya Somchaiyanon (P.S.), Siriwan Chandanachulaka (S.C2.), and Taiyatach Hirunrueng (T.H.) contributed to samples collection. Boonsong Ongphiphadhanakul (B.O.) contributed to the design of the study concept and supervision and critically revised the manuscript. All authors reviewed and approved the final manuscript.

\section{Acknowledgments}

This study was supported by the Ramathibodi Foundation.

\section{Supplementary Materials}

Table S1. Quantification of a tenfold serial dilution of 2019nCoV DNA control by real-time qPCR for the lower limit of detection assay. Figure S1. Location of markets in Pathum Thani from which wastewater samples were collected. The symbol represents sites that tested negative, the symbol represents sites that tested inconclusive, and the symbol represents sites that tested positive for SARS-CoV-2 RNA. Figure S2. Location of the markets from which wastewater samples were collected in Bangkok (Supplementary Materials)

\section{References}

[1] W. Ahmed, N. Angel, J. Edson et al., "First confirmed detection of SARS-CoV-2 in untreated wastewater in Australia: a proof of concept for the wastewater surveillance of COVID-19 in the community," The Science of the Total Environment, vol. 728, Article ID 138764, 2020.

[2] G. Medema, L. Heijnen, G. Elsinga, R. Italiaander, and A. Brouwer, "Presence of SARS-coronavirus-2 RNA in sewage and correlation with reported COVID-19 prevalence in the early stage of the epidemic in The Netherlands," Environmental Science and Technology Letters, vol. 7, no. 7, pp. 511516, 2020.

[3] P. Mecenas, R. T. d. R. M. Bastos, A. C. R. Vallinoto, and D. Normando, "Effects of temperature and humidity on the 
spread of COVID-19: a systematic review," PLoS One, vol. 15, no. 9, Article ID e0238339, 2020.

[4] A. Nemudryi, A. Nemudraia, T. Wiegand et al., "Temporal detection and phylogenetic assessment of SARS-CoV-2 in municipal wastewater," Cell Reports Medicine, vol. 1, no. 6, Article ID 100098, 2020.

[5] https:/www.who.int/publications/m/item/covid-19-targetproduct-profiles-for-priority-diagnostics-to-supportresponse-to-the-covid-19-pandemic-v.0.1.

[6] S. Wurtzer, V. Marechal, and J. M. Mouchel, "Evaluation of lockdown effect on SARS-CoV-2 dynamics through viral genome quantification in waste water, Greater Paris, France, 5 March to 23 April 2020," Euro Surveillance: bulletin Europeen sur les maladies transmissibles=European communicable disease bulletin, vol. 25, no. 50, 2020.

[7] Center for Disease Control and Prevention, National Wastewater Surveillance System (NWSS), Center for Disease Control and Prevention, Atlanta, GA, USA, 2021, https:// www.cdc.gov/coronavirus/2019-ncov/cases-updates/ wastewater-surveillance.html.

[8] A. Sharma, B. Preece, H. Swann et al., "Structural stability of SARS-CoV-2 virus like particles degrades with temperature," Biochemical and Biophysical Research Communications, vol. 534, pp. 343-346, 2021.

[9] S. M. Duan, X. S. Zhao, R. F. Wen et al., "Stability of SARS coronavirus in human specimens and environment and its sensitivity to heating and UV irradiation," Biomedical and Environmental Sciences: Biomedical and Environmental Sciences, vol. 16, no. 3, pp. 246-255, 2003.

[10] M. Guasp, C. Laredo, and X. Urra, "Higher solar irradiance is associated with a lower incidence of coronavirus disease 2019," Clinical Infectious Diseases, vol. 71, no. 16, pp. 2269-2271, 2020.

[11] M. Jaganmohan, Average Annual Temperature across India 2012-2020, Statista, Hamburg, Germany, 2021.

[12] M. Kumar, A. K. Patel, A. V. Shah et al., "First proof of the capability of wastewater surveillance for COVID-19 in India through detection of genetic material of SARS-CoV-2," The Science of the Total Environment, vol. 746, Article ID 141326, 2020.

[13] The Thai Meteorological Department: https://www.tmd.go.th/ en/index.php.

[14] World Health Organization (WHO), Laboratory Biosafety Guidance Related to Coronavirus Disease (COVID-19): Interim Guidance, WHO, Geneva, Switzerlandhttps://www. who.int/publications/i/item/WHO-WPE-GIH-2021.1.

[15] W. Ahmed, P. M. Bertsch, and A. Bivins, "Comparison of virus concentration methods for the RT-qPCR-based recovery of murine hepatitis virus, a surrogate for SARS-CoV-2 from untreated wastewater," Science of The Total Environment, vol. 739, 2020.

[16] The Department of Disease Control, Ministry of Public Health, and Thailand: https://covid19.ddc.moph.go.th/en.

[17] M. Patel, A. K. Chaubey, C. U. Pittman, T. Mlsna, and D. Mohan, "Coronavirus (SARS-CoV-2) in the environment: occurrence, persistence, analysis in aquatic systems and possible management," Science of The Total Environment, vol. 765, no. 142698, 2021.

[18] M. Ampuero, S. Valenzuela, and F. Valiente-Echeverría, "SARS-CoV-2 detection in sewage in santiago," Chile-Preliminary Results, 2020.

[19] S. Arora, A. Nag, J. Sethi et al., "Sewage surveillance for the presence of SARS-CoV-2 genome as a useful wastewater based epidemiology (WBE) tracking tool in India," Water Science and Technology, vol. 82, no. 12, pp. 2823-2836, 2020.

[20] S. Agrawal, L. Orschler, and S. Lackner, "Long-term monitoring of SARS-CoV-2 RNA in wastewater of the Frankfurt metropolitan area in Southern Germany," Scientific Reports, vol. 11, no. 1, Article ID 5372, 2021.

[21] C. F. Tso, A. Garikipati, A. Green-Saxena, Q. Mao, and R. Das, "Correlation of population SARS-CoV-2 cycle threshold values to local disease dynamics: exploratory observational study," JMIR public health and surveillance, vol. 7, no. 6, Article ID e28265, 2021.

[22] C. Li, C. Zhao, J. Bao, B. Tang, Y. Wang, and B. Gu, "Laboratory diagnosis of coronavirus disease-2019 (COVID-19)," Clinica Chimica Acta, vol. 510, pp. 35-46, 2020.

[23] A. Bivins, D. Kaya, K. Bibby et al., "Variability in RT-qPCR assay parameters indicates unreliable SARS-CoV-2 RNA quantification for wastewater surveillance," Water Research, vol. 203, Article ID 117516, 2021.

[24] D. Changsom, S. Saeng-aroon, and T. Thanadachakul, "Premarketing evaluation of real-time RT PCR test kits for SARSCoV-2 detection: Thailand emergency use authorization," National Institute of Health, vol. 62, no. 3, pp. 205-219, 2020.

[25] G. B. Barra, T. H. Santa Rita, P. G. Mesquita, R. H. Jácomo, and L. F. A. Nery, "Analytical sensitivity and specificity of two RT-qPCR protocols for SARS-CoV-2 detection performed in an automated workflow," Genes, vol. 11, no. 10, 2020.

[26] https://en.climate-data.org/asia/india/gujarat/ahmedabad$2828 /$.

[27] A. Hata, H. Hara-Yamamura, Y. Meuchi, S. Imai, and R. Honda, "Detection of SARS-CoV-2 in wastewater in Japan during a COVID-19 outbreak," The Science of the Total Environment, vol. 758, Article ID 143578, 2021.

[28] D. Zhang, H. Ling, X. Huang et al., "Potential spreading risks and disinfection challenges of medical wastewater by the presence of Severe Acute Respiratory Syndrome Coronavirus 2 (SARS-CoV-2) viral RNA in septic tanks of Fangcang Hospital," The Science of the Total Environment, vol. 741, Article ID 140445, 2020.

[29] D. L. Wannigama, M. Amarasiri, C. Hurst et al., "Tracking COVID-19 with wastewater to understand asymptomatic transmission," International Journal of Infectious Diseases, vol. 108, pp. 296-299, 2021.

[30] J. Alcoba-Florez, H. Gil-Campesino, D. G.-M. d. Artola et al., "Sensitivity of different RT-qPCR solutions for SARS-CoV-2 detection," International Journal of Infectious Diseases, vol. 99, pp. 190-192, 2020.

[31] J. Carrillo-Reyes, M. Barragán-Trinidad, and G. Buitrón, "Surveillance of SARS-CoV-2 in sewage and wastewater treatment plants in Mexico," Journal of Water Process Engineering, vol. 40, pp. 101815-101815, 2021.

[32] I. Michael-Kordatou, P. Karaolia, and D. Fatta-Kassinos, "Sewage analysis as a tool for the COVID-19 pandemic response and management: the urgent need for optimised protocols for SARS-CoV-2 detection and quantification," Journal of Environmental Chemical Engineering, vol. 8, no. 5, Article ID 104306, 2020. 